\title{
Tapered optical fibre sensor for detection of hydrocarbon spills in seawater
}

\author{
J.A. Sánchez-Martín*a, E. Bernabeu ${ }^{\mathrm{a}}$, A. Rodríguez-Aramendía ${ }^{\mathrm{a}}$, A. Villalba ${ }^{\mathrm{a}}$, E. Cruzado ${ }^{\mathrm{b}}, \mathrm{M}$. \\ Pardo de Santayana ${ }^{\mathrm{b}}$ \\ a Departamento de Óptica, Universidad Complutense de Madrid, Avda. Complutense s/n, \\ 28040 Madrid, Spain. \\ ${ }^{\mathrm{b}}$ CEPSA (Compañía Española de Petróleos S.A.), Campo de las Naciones, Ribera del Loira \\ 50.Edificio 1, 28042 Madrid, Spain.
}

\begin{abstract}
Three devices based on tapered optical fibres are used to determine the presence of pollutants in water, through the measure of their spectral transmittance. Tapered optical silica fibres, coated (or not) with metallic and dielectric layers ( $\mathrm{Al}$ or $\mathrm{Cu}$ and $\mathrm{TiO}_{2}$ ) are employed. It is found that, with our experimental arrangement, the presence of products derived from gasoline spills can be determined when we use the coated tapers. A complete characterization of the three different tapers is made in a wide spectral range $(1300-1650 \mathrm{~nm})$ and the wavelengths most suitable to detect and discern the hydrocarbons measured are identified. The results obtained show that these devices can be used for the early detection of oil spills in seawater in an industrial environment as simple and versatile sensors that can be self-cleaned with the movement of seawater.
\end{abstract}

Keywords: tapered optical fibre, optical fibre sensor, evanescent field, oil spills detection sea water, hydrocarbons, in situ sensing.

\section{INTRODUCTION}

The spill of hydrocarbons during loading and unloading in the refineries is a very important economic and environmental problem which has not been successfully solved. Early-warning devices, cheap and with minimal maintenance costs, able to monitor the specific areas where those processes are developed, are very interesting in an industrial environment because they could provide a fast response of the security mechanisms, thus minimizing the amount of spilled oil and its harmful effects. Several sensors have been employed to detect oil in water in a fast way based on many different technologies such as image analysis, laser-induced UV fluorescence, light scattering and turbidity, focused ultrasonic acoustics or fibre optic chemical sensors ${ }^{1}$. The majority of the instruments based on these technologies present varied limitations for field applications ${ }^{1}$.

In what respects to optical fibre technology, different sensors have been proposed, arousing great interest because of their good characteristics and variety of fields of application ${ }^{2}$. There are some examples of distributed sensing with bending-based fiber optic devices incorporating swelling polymers ${ }^{3}$ and fiber-optic chemical sensors with an organic cladding that absorbs the hydrocarbon and changes its refractive index $(\mathrm{RI})^{4,5}$. The most important problem that this kind of sensors presents for a continuous field use as an alarm system is that they are single-use, needing a cleaning process and eventually a recalibration outside the sensing area, after having been in contact with a hydrocarbon and before a new use. On the other hand, this type of optical fibre technology has the advantage of the possibility of integrating the transducers in an optical fibre network structure.

During the last decade distributed optical fibre sensors based on Brillouin effect have been proposed and successfully tested in the field ${ }^{6,7}$, but these devices operate linked to a pipeline because they measure changes in temperature or strain.

23rd International Conference on Optical Fibre Sensors, edited by José Miguel López-Higuera,

Julian Jones, Manuel López-Amo, José Luis Santos, Proc. of SPIE Vol. 9157, 91574E

(C) 2014 SPIE · CCC code: 0277-786X/14/\$18 · doi: 10.1117/12.2058667 
Other optical fibre sensors are based on the writing of long period gratings (LPG) in standard telecommunication fibres and have demonstrated to be successfully applicable in hydrocarbon detection ${ }^{8}$.

Tapered optical fibre have been widely employed during the last decades for sensing many physical magnitudes: temperature, strain, or refractive index $(\mathrm{RI})^{9}$. Used as a refractometer without any deposited layers, silica tapers present the limitation that they are unable to measure indices lower than the value of silica refractive index. The coating of tapers with metallic and dielectric layers permits to overcome these limitations, thus increasing the measurable range of indices and being able to apply to other fields, such as the seawater salinity measurement ${ }^{10-12}$.

Two methods of measurement are possible when dealing with coated tapers working as refractometers, namely, intensity (or power) and spectral transmittance (or reflectance). In the first case, the intensity variations produced by a change of the index of the medium surrounding the taper is measured with a single diode detector or a power meter. In the second one, a spectrometer is used to monitor the variations of the spectral transmittance curve, frequently through the detection of minima of transmittance that shift their position when the outer index changes.

In this paper the response of three types of sensors, all of them made with standard SMF-28 optical fibre, in contact with products derived from hydrocarbon solutions in seawater is measured. A naked tapered optical fibre was used in the first instance and then, a metallic layer (aluminium or copper) and a dielectric layer (titanium dioxide) were deposited on the taper. Their spectral transmittance was characterized, when five different products derived from hydrocarbons (fuel-oil, light crude, heavy crude, diesel and gasoline), were added to water. The results obtained are presented, showing the capacity and potential of this type of optical fibre sensor to become in the future candidates to be used as in-situ alarm systems to detect oil spills on seawater surface. The salient features of the sensors presented are their versatility, capability of integration in an optical fibre network, easily measurement, low price and the possibility of a continuous measuring without the need of cleaning or re-calibration, since they can be self-cleaned with water in motion.

\section{EXPERIMENTAL SETUP AND MEASUREMENTS}

The optical fibre tapers were fabricated using the well-known travelling-burner technique. Several uniform-waist tapers were made with the following geometrical values were: total length: $18,3 \mathrm{~mm}$; transition length: $10,98 \mathrm{~mm}$; waist length: $6,34 \mathrm{~mm}$; diameter waist: $40 \mu \mathrm{m}$. The scheme of the different parts of the taper is shown in Figure 1. As it has said before, for some tapers metallic (aluminium or copper) and dielectric (titanium dioxide) layers are deposited on the tapered region. After this process, the tapers were fixed to a silica sample holder taking care that no undesirable curvature is induced on them.

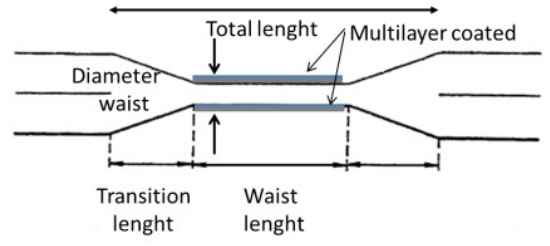

Figure 1.Optical fibre taper scheme.

The experimental setup for the characterization of the devices in the laboratory can be seen in Figure 2. We have used a broadband light source, Avantes AvaLight-HAL, and, as a detector, a Spectrometer Avantes AvaSpec-NIR256-1.7. The measuring procedure was as follows: first, the sensor was introduced in Mediterranean seawater collected directly in the Bay of Algeciras to take a reference measurement. Then, the product derived from hydrocarbon was added to seawater, and the transmittance variation was registered. After that the sequence was repeated again to check if the water in motion is able to clean the taper and if the measurement was repetitive. The concentration of the product in seawater (from $1 \%$ by volume to $25 \%$ by volume) was varied and the above-mentioned products mentioned above were added to all the measured tapers in due order. The taper was placed on the mixture surface to ensure a good contact with the product. During the measuring process the mixture was stirred by a rotary motor. The refractive index of the used products employed are ${ }^{13,14}$ : gasoline: 1,43; fuel-oil: 1,46; diesel: 1,47 and Arabian light and heavy crude: 1,50. Although all the tapers were employed for all the measurements, only representative results for each type are presented, the results being similar for each taper of the same type. 


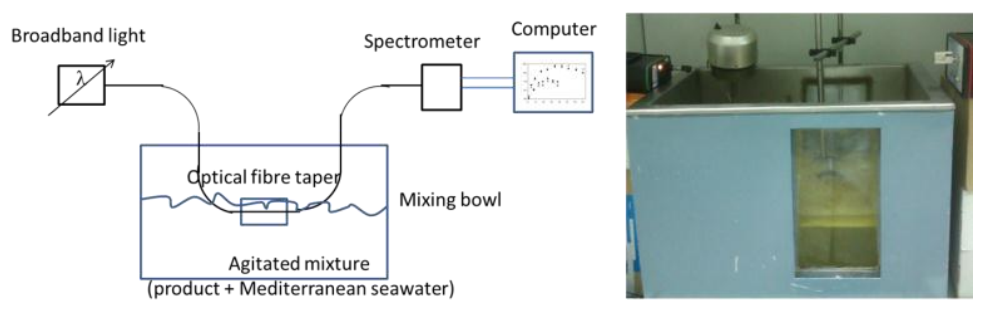

Figure 2. Scheme of the experimental setup used to measure the response of the three tapers with the solution of hydrocarbons on seawater (left) and image of it (right).

By way of example the results obtained for a concentration of $10 \%$ by volume of hydrocarbon in seawater are shown in Figure 3. It is remarkable that by concentration higher than $1 \%$ in volume the results are similar for all the measurements done. Also, the measurement repeatability after cleaning and between different tapers of the same type was very high, and the response time was less than 5 seconds (practically real time). Also it was checked that all the hydrocarbons except fuel oil, due to its higher viscosity and density, were readily cleaned only with seawater in motion with variations of less than 5\% between measurements. Fuel oil, on the other hand, remained adhered to optical fibre taper and only could be cleaned with gasoline or another organic solvent.
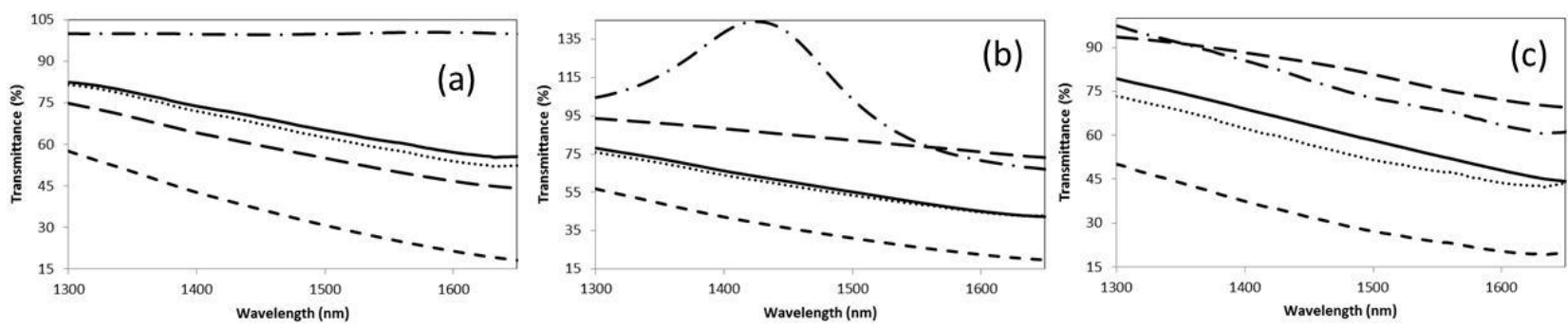

Figure 3. Spectral transmittance of silica taper (a), aluminium taper (b) and copper taper (c) for a 10\% in volume solution of: gasoline (line and dots), crude oil (dots), heavy crude (continuous line), fuel-oil (long segments) and diesel (short segments) in seawater.

\section{RESULTS ANALYSIS}

As it can be seen in Figure 3 the spectral response is analogous for the three tapers and for the five substances, except the gasoline measurement for the aluminium taper due to a Surface Plasmon Resonant formation around $1440 \mathrm{~nm}$ in the reference measurement with seawater. This taper provides around $1440 \mathrm{~nm}$ enough variation in response between the products to allow selective detection of the type of product. Generally, the response increases smoothly for all the spectra measured, and the maximum variation is for wavelengths around $1600-1650 \mathrm{~nm}$. As it could expected the taper without metallic deposition is not able to detect gasoline because of its low refractive index lower than silica itself. Both coated tapers are able to detect all the products although its sensitivity is different. In order to facilitate the quantitative comparison between the results of each taper for each of the hydrocarbons, in Table 1 the variation respect the transmission in seawater is represented for $1550 \mathrm{~nm}$, due to it is the communications representative wavelength.

Table 1. Variation relative $(\mathrm{dB})$ to seawater of uncoated taper and coated tapers for oil collection in $1550 \mathrm{~nm}$.

\begin{tabular}{|c|c|c|c|}
\hline Hydrocarbon & Silica Taper & Al Taper & Cu Taper \\
\hline Gasoline & - & 0,91 & 1,8 \\
\hline Fuel oil & 3,0 & 1,0 & 1,2 \\
\hline Diesel & 5,9 & 5,8 & 6,0 \\
\hline Light Crude & 2,3 & 3,1 & 3,2 \\
\hline Heavy Crude & 2,1 & 3,0 & 2,8 \\
\hline
\end{tabular}


As it can be seen in Table 1 silica taper is not appropriate for gasoline, but presents good detection for the rest of substances measured even better than the metallic coated tapers for fuel oil and diesel. The metallic coated tapers are able to detect all the products although with slightly different response variation. Except for heavy crude the variation is slightly higher for a copper deposition, especially for gasoline.

\section{CONCLUSIONS}

From the above experimental study and analysis it can be concluded that optical fibre tapers with a metallic (aluminium and copper) depositions used as sensors for oil spill present very interesting properties of repeatability after cleaning, response time, detection capability, repeatability among different sensors and self-cleaning with water in motion (except for fuel-oil). This means that we can use these devices for early warning of oil spill in seawater in an industrial environment. Also, a selective detection of gasoline can be provided with an aluminium-coated taper working around a wavelength of $1440 \mathrm{~nm}$.

\section{ACKNOWLEDGMENT}

The authors would like to thank Drs. M.C. Navarrete, N. Diaz-Herrera and A. González-Cano for the optical fibre tapers manufacturing and their valuable comments. This work was supported by CEPSA (project ref. 161-2012 UCM).

\section{REFERENCES}

[1] Lee, K., Neff, J., [Produced Water. Environmental Risks and Advances in Mitigation Technologies], Springer, New York, 57-88 (2011).

[2] López-Higuera, J.M., [Handbook of Optical Fibre Sensing Technology], John Wiley\&Sons, Chichester (2002).

[3] MacLean, A., Moran, C., Johnstone, W., Culshaw, B., Marsh, D., Parker, P., "Detection of hydrocarbon fuel spills using a distributed fibre optic sensor" Sensor Actuat. A-Phys. 109, 60-67 (2003).

[4] McCue, R.P., Walsh, J.E., Walsh, F., Regan, F., "Modular fibre optic sensor for the detection of hydrocarbons in water" Sensor Actuat. B-Chem 114, 438-444 (2006).

[5] http://www.petrosense.com/

[6] Nickles, M.,"Long-distance fiber optic sensing solutions for pipeline leakage intrusion and ground movement detection" Proc. SPIE 7316, 1-13 (2009).

[7] Falate, R., Kamikawachi, R.C., Müller, M., Kalinowski, H.J., Fabris, J.L., "Fiber optic sensors for hydrocarbon detection" Sensor Actuat. B-Chem 105 430-436 (2005).

[8] Lee, B. "Review of the present status of optical fiber sensors" Opt. Fiber Technol. 9 (2), 57-59 (2003).

[9] Lacroix, S., Black, R.J., Veilleux, C., Lapierre, J., "Tapered single-mode fibers: external refractive-index dependence" Appl. Optics 25 (15), 4421-4425 (1986).

[10]Esteban, O., Navarrete, M.C., Gonzalez-Cano, A., Bernabeu, E., "Measurement of the degree of salinity of water with a fiber-optic sensor" Appl. Optics 41 (8) 5267-5271 (1999).

[11] Diaz-Herrera. N, Navarrete, M.C., Esteban, O., González-Cano, A., "A fibre-optic temperatura sensor based on the deposition of a thermochromic material on an adiabatic taper" Meas. Sci. Technol. 15 (2), 353-358 (2004).

[12] Diaz-Herrera, N., Esteban, O., Navarrete, M.C., Le Haitre, M., González-Cano, A., "In situ salinity measurements in seawater with a fibre-optic probe" Meas. Sci. Technol. 17 (8), 2227-2232 (2006).

[13] Jones, J.C., [Hydrocarbons: Physical Properties and Their Relevance to Utilisation], BookBoon, London, 1-110 (2010).

[14] http://www.cepsa.com/ 